\title{
Transferable Drug Resistance in Enterobacteria Isolated from Urban Infants
}

\author{
E. C. MOORHOUSE, * L.R.C.P.\&S.I., D.P.H., M.C.PATH.
}

British Medical fournal, 1969, 2, 405-407

\begin{abstract}
Cummary : Antibiotic-resistant enterobacteria, the vast $S$ majority of which carried transmissible $\mathbf{R}$ factors, were isolated from 81 out of a total of 100 healthy infants. There was surprisingly little correlation between previous antibacterial therapy and the resistant enterobacterial flora.
\end{abstract}

\section{Introduction}

In 1967 in Dublin non-pathogenic strains of Escherichia coli with multiple transferable antibiatic resistance $(\mathrm{R}+)$ were isolated from the faeces of a small number of infants who had not been in hospital and who had not had antibacterial therapy (Moorhouse and McKay, 1968). A survey was made to determine the incidence of non-pathogenic drug-resistant $\mathrm{R}+$ enterobacteria in normal healthy infants in Dublin, and this paper describes the findings.

\section{Materials}

During November 1967 health visitors, who are Stateregistered nurses, visited the homes of children under 2 years of age and arranged to collect a sample of faeces from the infant. From the mother they obtained a full personal history of each infant, including details of any antibacterial therapy received by the infant since birth or by a "contact" of the infant within the previous three months. A contact was any person living in the infant's home. The identity of the drugs received was confirmed in all cases by contacting the medical practitioner who had prescribed them. Infants included in the survey were all less than 2 years of age, had never been patients in a hospital apart from birth, and were "healthy" at the time of the nurse's visit. "Healthy" was defined as having no abnormal signs or symptoms, not attending a doctor at the time, nor for at least three weeks before the visit, and not receiving any antibacterial therapy. The number of infants who fulfilled these criteria totalled 100, 58 males and 42 females. Seventy-eight were less than 12 months old and 47 of these were less than 6 months. Their homes were distributed throughout all areas of the city.

Culture Media.-Liquid medium contained 25 g. Oxoid No. 2 dehydrated nutrient broth per litre. Solid medium contained 51.5 g. Oxoid No. 3 dehydrated MacConkey agar per litre.

Sensitivity Discs.-Oxoid Multodisk containing $25 \mu \mathrm{g}$. ampicillin, $25 \mu \mathrm{g}$. streptomycin, $50 \mu \mathrm{g}$. tetracycline, $50 \mu \mathrm{g}$. chloramphenicol, $200 \mu \mathrm{g}$. furazolidone, and $30 \mu \mathrm{g}$. nalidixic acid, and Oxoid individual sensitivity discs.

Antibiotics Incorporated in Solid Medium.-Tetracycline (Lederle), chloramphenicol (Parke-Davis), neomycin (Glaxo), and nalidixic acid (Bayer) were kindly supplied by the manufacturers. Ampicillin (Beecham), streptomycin (Glaxo), and furazolidone (Smith Kline and French) were commercial preparations.

Recipient Strain in Transfer Experiments.-The recipient

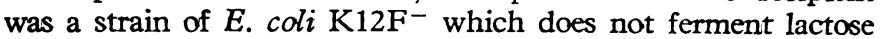

- Professor of Clinical Microbiology, Royal College of Surgeons in Ireland, Dublin 2. and requires methionine, tryptophan, and proline for growth. It is resistant to $100 \mu \mathrm{g}$. of nalidixic acid per ml. but sensitive to all other relevant drugs.

Enteropathogenic E. coli Antisera.-E. coli O B agglutinating sera (Wellcome).

Methods
Each specimen of faeces was spread across two MacConkey
agar plates to obtain a confluent bacterial lawn and a
Multodisk was applied to each plate. The plates were incubated
at $37^{\circ}$ C. overnight. Any clearing around the discs was taken
to indicate drug sensitivity, and all drug-sensitive bacterial
strains were discarded. The appearance of bacterial growth
around any of the discs was noted-that is, whether it was
confluent or discrete isolated colonies. The growth in contact
with any of the discs was plated on MacConkey agar for single
colonies. Lactose-fermenting and non-fermenting colonies
were identified by the following tests: motility, sugar fermenta-
tion, reduction of phenylalanine, urease activity, growth in
KCN medium, and indole production. Several single colonies
of the identified genus were then retested for antibiotic sensi-
tivity. The strain of $E$. coli with resistance to the greatest
number of drugs was tested for transfer of resistance. Where
resistant $E$. coli was not found, other resistant identified species
were tested for R transfer. Several colonies from all strains of
$E$. coli isolated, sensitive and resistant, were tested for agglu-
tination with enteropathogenic $E$. coli antisera.

Resistance Transfer.-Each resistant strain was grown in mixed broth culture with the recipient $E$. coli K12 strain. After overnight incubation the centrifuged deposit of the mixture was plated on MacConkey agar containing $20 \mu \mathrm{g}$. of nalidixic acid per ml. plus one of the drugs to which the strain was resistant (Moorhouse and McKay, 1968). Where resistance transfer occurred, the $\mathrm{R}+E$. coli $\mathrm{K} 12$ grew on the plates. It was identified by its inability to ferment lactose, amino-acid dependence, and resistance to nalidixic acid. The resistance acquired by the recipient strain was confirmed by testing with the same Multodisk as was used for the screening sensitivity tests and also with individual discs of each drug at a level of $10 \mu \mathrm{g} . / \mathrm{ml}$. Where no transfer of resistance occurred we repeated the experiment at least twice before deciding that the resistance was not transmissible.

\section{Results}

Antibiotic Sensitivity Tests and Resistance Transfer.Enteric bacteria resistant to one or more of the antibiotics tested were isolated from the faeces of 81 of the 100 infants. Resistant $E$. coli were isolated from 71: they appeared in apparently pure growth from 43 specimens, in mixed growth with other resistant genera from 16 , and mixed with sensitive enterobacteria from 12 . The 81 bacterial strains tested for transferable drug resistance included 71 strains of $E$. coli, 6 of Klebsiella, and 4 of Proteus. The percentage of these 81 strains resistant to each of the antibiotics is shown in Table I. Over $60 \%$ were resistant to ampicillin, streptomycin, and tetracycline, $16 \%$ were resistant to chloramphenicol, and $17 \%$ 
to neomycin. Only $1 \%$ ( 1 strain) was resistant to furazolidone and none was resistant to nalidixic acid. The resistance patterns of the 81 strains and the results of transfer experiments are listed in Table II. Sixty-eight of these strains transferred their resistance to $E$. coli $\mathrm{K} 12$. There were 29 strains resistant to one antibiotic only and 17 of these transferred their resistance (four could not be tested for transfer because they had lost their resistance on storage). Twenty-five strains were resistant to two drugs and all but one transferred one or both resistances. The 27 strains resistant to three or more antibiotics all transferred resistance; 14 of these failed to transfer their entire resistance pattern.

\begin{tabular}{|c|c|c|c|c|c|c|c|c|}
\hline \multirow{2}{*}{$\begin{array}{l}\text { No. of Faecal } \\
\text { Specimens } \\
\text { Exa nined }\end{array}$} & \multirow{2}{*}{$\begin{array}{c}\text { Percentage } \\
\text { with Resistant } \\
\text { Enterobacteria }\end{array}$} & \multicolumn{7}{|c|}{ Percentage resistant to: } \\
\hline & & A & $\mathrm{S}$ & $\mathrm{T}$ & $\mathrm{C}$ & $\mathbf{N}$ & $\mathrm{Fu}$ & $\mathrm{Nx}$ \\
\hline 100 & 81 & 62 & 63 & 67 & 16 & 17 & 1 & 0 \\
\hline
\end{tabular}

$\mathrm{A}=$ Ampicillin. $\mathrm{S}=$ Streptomycin. $\mathrm{T}=$ Tetracycline. $\mathrm{C}=$ Chloramphenicol. $\mathrm{N}=$ Neomycin. $\mathrm{Fu}=$ Furazolidone. $\mathrm{Nx}=$ Nalidixic acid.

TABLE II.-Resistance Patterns, Number of Strains with Transferable Drug Resistance $(R+)$, and Antibacterial Therapy Received by Infants and Contacts

\begin{tabular}{|c|c|c|c|c|}
\hline \multirow{2}{*}{$\begin{array}{l}\text { Resistance } \\
\text { Pattern }\end{array}$} & \multirow{2}{*}{$\begin{array}{l}\text { No, with Each } \\
\text { Pattern* }\end{array}$} & \multirow{2}{*}{$\begin{array}{c}\text { No. of } \\
R+ \\
\text { Strainst }\end{array}$} & \multicolumn{2}{|c|}{ Previous Antibacterial Therapy $\ddagger$} \\
\hline & & & Infants & Contacts \\
\hline $\begin{array}{l}\text { Sensitive } \\
\text { A } \\
\text { S } \\
\text { T } \\
\text { N } \\
\text { A S } \\
\text { A T } \\
\text { S T } \\
\text { A Fu } \\
\text { A N } \\
\text { A S T } \\
\text { S T C } \\
\text { ST N } \\
\text { A S T N } \\
\text { A S T C }\end{array}$ & $\begin{aligned} & 19 \\
& 6(2 \text { Klebsiella) } \\
& 6 \\
& 16 \text { (3 Proteus) } \\
& 1 \\
& 12 \\
& 5 \\
& 6 \\
& 1 \\
& 1 \\
& 8 \\
& 1 \\
& 1 \\
& 5 \\
& 6 \text { (2 Klebsiella) }\end{aligned}$ & $\begin{array}{r}0 \\
2 \\
4 \\
10 \\
1 \\
12(4) \\
5(3) \\
6(1) \\
0 \\
1 \\
8(2) \\
1(1) \\
1(3) \\
5(3) \\
6(3)\end{array}$ & $\begin{array}{l}\mathrm{P}+\mathrm{T}(2) ; \mathrm{T}(2) \\
\mathrm{A}(1) \\
0 \\
\mathrm{P}(2) ; \mathrm{A}(1) ; \mathrm{T}(1) ; \mathrm{N}(1) \\
0 \\
\mathrm{~A}(3) ; \mathrm{T}(3) \\
\mathrm{P}(1) \\
\mathrm{S}(1) \\
\mathrm{P}(1) \\
0 \\
\mathrm{P}(2) ; \mathrm{T}(1) \\
\mathrm{P}(1) \\
\mathrm{P}(1) \\
0 \\
\mathrm{P}(3) ; \mathrm{Su}(1)\end{array}$ & $\begin{array}{l}0 \\
0 \\
\mathrm{~A}(1) ; \mathrm{T}(1) \\
\mathrm{P}+\mathrm{S}(1) ; \mathrm{P}(1) \\
0 \\
\mathrm{~S}(1) \\
0 \\
\mathrm{P}(1) \\
0 \\
0 \\
0 \\
0 \\
0 \\
\mathrm{~T}(2) \\
0\end{array}$ \\
\hline $\begin{array}{l}\text { A S C } \underset{\text { N }}{N} \\
\text { A S T }\end{array}$ & 1 ( 1 Kl Klebsiella $)$ & $\frac{1}{5(5)}$ & $\stackrel{0}{\mathrm{~T}}(1) ; \mathrm{N}(1)$ & $\begin{array}{l}0 \\
0\end{array}$ \\
\hline Total & 81 & 68 & 30 & 8 \\
\hline
\end{tabular}

* E. coli strains unless otherwise stated.

+ Number of strains which transferred only a part of their resistance pattern are given in parentheses.

$¥$ Number of infants who received the drug is given in parentheses.

$\mathbf{P}=$ Penicillin. Su $=$ Sulphonamides.

Enterupathogenic Serotypes.-None of the $E$. coli strains isolated were of known enteropathogenic serotypes.

\section{Previous Antibacterial Therapy}

Antibacterial drugs received by any of the 100 infants from birth are listed in Table II. Also listed are the drugs received by contacts of the infants within the previous three months. Four $(21 \%)$ of the 19 infants from whom we isolated only sensitive enteric bacteria had received antibiotics. None of their contacts had had any drugs within the previous three months. Of the 81 infants who excreted resistant enterobacteria, $26(32 \%)$ had been treated with an antibiotic or sulphonamide. Eight others had contacts who had received antibacterial therapy.

The duration of therapy was never less than three days and never longer than one week for all treated infants. The intervals between treatment and collection of the faecal specimen varied from 4 to 44 weeks. Exclusion of treated infants and those with treated contacts from a total of 81 infants with resistant enterobacteria left $47(58 \%)$ who had no history of antibacterial therapy or close contact with anyone who had received an antibiotic or a sulphonamide within the previous three months.

Effect of Drugs on Faecal Bacteria.-Culture of some specimens gave confluent bacterial growth up to the disc, while with others only a minority of the growth was resistant and isolated colonies were seen within zones of inhibition. A total of 44 specimens on culture gave confluent bacterial growth up to the discs ; $15(34 \%)$ were from infants who had received antibacterial therapy. As the majority of the 26 treated infants had received either a penicillin or a tetracycline compound, we examined our results to determine whether therapy with either drug had acted as a selective agent (see Table III). Eighteen infants had been treated with penicillin or ampicillin, and $7(39 \%)$ of these excreted faeces which on culture gave confluent growth up to the ampicillin disc as compared with $20(24 \%)$ of the 82 infants who never had penicillin. Ten infants had received a tetracycline compound and two $(20 \%)$ of these excreted enterobacteria which grew confluently up to the tetracycline disc, as compared with 31 (34\%) of the 90 infants who had not had tetracycline. Faeces from infants who had recently (within the previous three months) received a course of penicillin or tetracycline did not show any higher incidence of confluent growth up to the corresponding disc.

TABLE III.-Effect of Penicillin and Tetracycline Compounds on the Faecal Bacteria

\begin{tabular}{|c|c|c|c|}
\hline \multirow[t]{2}{*}{ Category } & \multirow[t]{2}{*}{ No. } & \multicolumn{2}{|c|}{$\begin{array}{l}\text { No. of Specimens Showing } \\
\text { Confluent Growth } \\
\text { Around Discs }\end{array}$} \\
\hline & & Ampicillin & Tetracycline \\
\hline $\begin{array}{l}\text { All infants } \ldots \\
\text { Infants treated with penicillin or ampicillin } \\
\text { Infants treated with tetracycline } \ldots\end{array}$ & $\begin{array}{r}100 \\
18 \\
10\end{array}$ & $\begin{aligned} & 27(27 \%) \\
& 7(39 \%)\end{aligned}$ & $\begin{array}{l}33(33 \%) \\
2(20 \%)\end{array}$ \\
\hline
\end{tabular}

\section{Possible Sources of Resistant Strains}

Of the 81 infants with resistant strains 16 were less than 3 months old and were born in a hospital. Three others had contacts who had been in hospital during the previous year. Another eight infants had contacts who had been treated with antibiotics during the previous three months.

Number of Siblings.-Of the 81 infants with resistant strains $25(31 \%)$ were only children.

\section{Discussion}

The number of infants who excreted resistant enteric bacteria in this survey is remarkably high when one considers that these were normal healthy infants living in populated areas of the city, the majority $(78 \%)$ of whom were less than 1 year old. It is interesting to compare the incidence of resistant enteric bacteria in this population with that in other published investigations. Lewis (1968) found that $24 \%$ of 300 strains of $E$. coli isolated from faeces were drug-resistant. The specimens had been sent to the laboratory for examination for faecal pathogens, and, as the author pointed out, could not be regarded as a random sample of normal faeces. The proportion (24\%) of drug-resistant strains is very low in comparison with ours $(81 \%)$. However, the method of selection was different in the two studies, since Lewis examined single colonies taken from drug-free medium while we made a direct selection for drugresistant bacteria in a primary faecal inoculum. This difference in technique might also explain the relatively low proportion (37\%) of resistant E. coli which Cooke (1968) isolated from the faeces of 49 persons who either worked in the hospital or were recently admitted patients.

Strains isolated from 68 of our 100 infants had transferable drug resistance. Smith and Halls (1966) isolated $\mathrm{R}+E$. coli from the faeces of 15 out of a total of 24 adults who looked after farm animals. While it might be supposed that these persons acquired their resistant $\mathrm{R}+E$. coli from drug-treated livestock, the proportion (62\%) of individuals excreting resistant $\mathrm{R}+$ enteric bacteria is nearer ours. Moorhouse and McKay (1968) isolated R $+E$. coli from 15 out of a total of 22 infants on admission to hospital. Of these 15, 6 (40\%) 
had no previous history of antibacterial therapy and had not been in hospital.

It is generally accepted that therapy with a particular drug selects bacteria resistant to the drug, which may result in a predominantly resistant bacterial flora. It was surprising therefore to find that only $7(39 \%)$ of the 18 infants who had received either penicillin or ampicillin had a predominantly ampicillin-resistant bacterial flora. There was some evidence, however, to suggest that penicillin or ampicillin therapy did have a selective effect, because a higher proportion of treated than of untreated infants had confluent growth up to the ampicillin disc. There was no evidence from our small number of tetracycline-treated infants that the drug had acted as a selective agent ; the proportion of infants showing a predominantly tetracycline-resistant enterobacterial flora was higher in the untreated than in the treated group.

Sensitive strains only were isolated from 19 infants; four of these had received antibacterial therapy. If these drugs had exerted any selective pressure, we might have expected to isolate resistant bacteria from the faeces with our direct selection method.

It is impossible to determine the source of any of these 81 resistant enterobacterial strains. The 16 infants who were less than 3 months old and born in a hospital might have acquired their resistant strains from members of the hospital staff or other mothers in the wards. Apart from this possibility in
16 cases, the infants must have acquired their resistant strains from others in their homes. Three infants had contacts who had been in hospital. These three contacts might have acquired resistant enterobacteria while in hospital (Moorhouse and McKay, 1968) and subsequently infected the infants. Eight other contacts who had received antibiotics were possible sources of resistant enterobacteria. Twenty-five of the 81 infants were only children. We must assume that they were infected with resistant strains from a parent or other adult in the home.

The results of the survey confirmed our opinion that resistant enteric bacteria, most of them carrying transmissible $\mathrm{R}$ factors, are widely disseminated in the infant population of this city.

This work was supported by a grant from the Medical Research Council of Ireland. I wish to thank Dr. J. B. O'Regan, Chief M.O.H., Dublin, who made this survey possible, and Miss E Mattimoe, of his department, who organized the collection of the specimens, etc. My gratitude to Miss J. O'Donovan for her valuable technical assistance and to Dr. Naomi Datta for advice and criticism.

REFERENCES

Cooke, E. M. (1968). Fournal of Pathology and Bacteriology, 95, 101. Lewis, M. J. (1968). Lancet, 1, 1389.

Moorhouse, E. C., and McKay, L. (1968). British Medical fournal, 2. 741 .

Smith, H. W., and Malls, S. (1966). British Medical fournal, 1, 266.

\title{
Drug Resistance and $\mathbf{R}$ Factors in the Bowel Bacteria of London Patients before and after Admission to Hospital
}

\author{
NAOMI DATTA,* M.D., M.C.PATH.
}

\begin{abstract}
Summary : The content of drug-resistant coliform $\checkmark$ bacteria in faecal specimens collected before admission from patients awaiting non-urgent surgery were compared with specimens collected in hospital. Resistant strains of Escherichia coli were isolated from $52 \%$ of preadmission specimens and were present in large numbers in $28 \%$. Tetracycline, sulphonamide, and streptomycin resistance were commonest : $60 \%$ of resistant strains carried transmissible $\mathbf{R}$ factors and multiple resistance was commoner than single. No characteristically resistant intestinal bacteria of any genera were found in hospital specimens as compared with those from outside.
\end{abstract}

\section{Introduction}

Over the last decade there has been clear evidence of a rapidly increasing incidence of antibiotic resistance in salmonella, shigella, and enteropathogenic types of Escherichia coli all over the world. At the present time something like $50 \%$ of isolates of these pathogens are resistant to one or more antibacterial drugs (Manten, Guinée, and Kampelmacher, 1966; H. W. Smith, 1966 ; Watanabe, 1966; Lebek, 1967; Anderson, 1968b ; Davies, Farrant, and Tomlinson, 1968a). The resist-

* Senior Lecturer in Bacteriology, Royal Postgraduate Medical School, London W.12. ance is for the most part determined by $R$ factors. The observed increase in the proportion of enteric pathogens resistant to drugs dates from about 1959 , when $\mathrm{R}$ factors were discovered, but is nevertheless a true increase and not merely a reflection of greater awareness of the problem.

The occurrence of antibiotic resistance in enteric pathogens is of obvious clinical importance and is well documented. Resistance in this group might be supposed to have become common as a result of the treatment of diarrhoeal disease with antibiotics, with consequent selection of resistant strains.

There is less information available on the incidence of resistance and of $\mathbf{R}$ factors in the normal bowel bacteria of healthy people. $\mathbf{R}$ factors in these bacteria present two possible dangers. Firstly, they may be transferred to enteric pathogens within the bowel of infected patients. There was epidemiological evidence for such transfer in Japan at the time of discovery of $\mathrm{R}$ factors (see Watanabe, 1963), and since then in other parts of the world-for example, Davies et al. (1968b). Secondly, and perhaps more important, resistant bacteria which are harmless in the bowel may infect the urinary tract or cause other parenteral infections.

$E$. coli, like salmonellae and shigellae, is normally drugsensitive. $\mathrm{R}$ factors, relatively easily detected in these species, are transmissible to many other bacterial genera, including those, such as Klebsiella, Proteus, and Pseudomonas, which are inherently resistant to certain antibacterial drugs. Acquisition 